vapour, and a cyclic process was traced. The water vapour attacked the heated filament, producing a volatile oxide of tungsten and atomic hydrogen; the oxide which became deposited on the bulb, was again reduced by the hydrogen, leaving metallic tungsten and forming water vapour, which again attacked the filament. Even when practically every trace of water vapour was removed, however, a certain blackening of the bulb still occurred, and this was eventually found to be occasioned by evaporation of the metal. To overcome this, nitrogen or some other inert gas is introduced into the bulb at about atmospheric pressure, and this is one of the features of the new lamp.

This, however, introduced another effect. The filament is more rapidly cooled by the convection currents induced in the gas, and in consequence more energy is required to maintain the temperature. With filaments of large diameter this is of less relative importance, but with filaments of the usual size the loss was found actually to reduce the efficiency in spite of the higher temperature, as the small filaments are cooled relatively more rapidly by the convection currents. As a result the high-temperature half-watt lamps are only made in large sizes-from 600 c.p. upwards-and in order to diminish this cooling effect the filaments are constructed in the form of a helix of very small pitch. Last week's issue (January 15) of Electrical Engineering is devoted largely to the new lamp, and the opinions of leading central station engineers in various parts of the country upon it are quoted.

\section{THE ASSOCIATION OF PUBLIC SCHOOL SCIENCE MASTERS.}

THE annual meeting of the Association of Public School Science Masters was held at the Imperial College of Science and Technology on January $13-14$. The president, Prof. H. B. Baker, F.R.S., in his address, extracts from which are given separately in this issue, regretted that so few science masters were engaged in research, and suggested that the interest of boys would be stimulated by the thought that such work was being carried out in the laboratory attached to their own school. Mr. C. E. Ashford (Dartmouth), in seconding a vote of thanks, disagreed with this view, and, speaking as a headmaster, maintained that it was of greater importance for a schoolmaster to spend his spare time in the playing fields getting to know his boys than it was for him to be undertaking research in the laboratory.

On the afternoon of the first day an interesting demonstration of the application of the gyroscope to mono-rail traction was given by his Excellency Monsieur Pierre Schilowsky, who exhibited a model of a new and improved forn of the appliance he has recently invented. Mr. H. O. Hale (Oundle) read a paper upon agricultural experiments in public schools; he urged that agricultural research was well within the capacity of the average boy, and was more real than most of the "mock research" carried out in the chemical laboratories. The idea is excellent, and many of the results obtained were of considerable interest it was, however, rather disappointing to find during the course of the subsequent discussion that much of the work, and even of the nbservations, were made for, instead of by, the boys themselves: the impression left being that, although the "experiments" afforded the foundation of a useful future hobby, they did not, under the conditions which prevail at present, provide a basis for a scientific education.

Wednesday morning was occupied by a discussion upon the "Present Condition of Science Teaching in Public Schools," which was opened by Dr. E. H. Tripp (Bedford) and Mr. J. R. Eccles NO. 2308, VOL. 92]
(Holt). Dr, Tripp deplored that the pamphlet published by the Board of Education in 1906 referred to a few only of the public schools, and that its aim was to state facts rather than to make suggestions; he urged the need of a fresh report which should not only state the conditions under which science was taught in all schools represented by the Headmasters' Conference, but should ccntain expressions of opinion from external authorities, e.g. university teachers and employers of ex-public school boys engaged in scientific occupations. He maintained that the chief drawbacks to progress in science teaching were $(a)$ the undue preponderance of literary headmasters; $(b)$ the conservative influence of the older universities; and $(c)$ the evils of the present examination system. The address was chiefliv of a destructive nature, and the subsequent discussion, although well maintained, was leśs fruitful in producing constructive proposals than in pointing out the defects of the existing system.

The discussion opened by Mr. D. Rintoul (Clifton) upon the "Place of Acoustics in a School Course of Physics," fell rather flat, owing, probably, to the uranimity of the members in considering that, whilst acoustics afforded a valuable introduction to the study of the wave theory, the difficulty in devising suitable laboratory exercises made it educationally the least valuable branch of physics. The most useful suggestion was that made by Mr. G. F. Daniell, that the determination of the velocity of sound in various gases might be introduced into the ordinary work of the chemical laboratory; he urged that if this were done something would have been accomplished towards breaking down the watertight compartment which too often separated chemistry from physics.

Mr. H. A. Wootton (Westminster) read a paper upon the "Relative Educational Value of Physics, Chemistry, and Biology," maintaining that chemistry, when properly taught, was the most useful subject. During the discussion which followed the paper it was pointed out that it was impossible to teach chemistry without also giving considerable instruction in physics, and several speakers urged that organic chemistry should $\mathrm{b}:$. commenced at an eariier age than is at present the practice.

At the business meeting, Sir William Osler, F.R.S., Regius professor of medicine at Oxford, was elected president of the association for I9I5.

\section{SCIENCE IN THE PUBLIC SCHOOLS. ${ }^{1}$}

NE of the chief difficulties which besets a science master is that few of his colleagues will have sympathy with his work. There are some, but I am afraid not very many, classical scholars who have some knowledge of studies which are so different from their own, but, too often, there is actual hostility on their part to science subjects, and since the first years of a boy's life are usually under the charge of a classical master, there is often instilled into his mind a contempt for the subjects which may be useful to him in his after life.

In most schools which I know, there is a system of selection of the boys by which those of the best ability are induced to continue on the classical side. It is, with comparatively few exceptions, only the weaker boys, or those whose ability has escaped notice, who are allowed to make science their chief study. But, in spite of this fact, which is known to most schoolmasters, how often is it triumphantly declared that a boy who has been educated on the classical side of a school is superior to one brought up on the science side? I wish, for just one year, that the science

1 From the presidential address delivered to the Association of Public School Science Masters on January $\pi_{3}$ by Prof. H. B. Baker, F.R S. 
masters could have their pick of the boys in all the public schools. I warrant that that statement would never be made again. I have often urged on headmasters the advisability of allowing more boys of pronounced ability to do more science at school. Over and over again I have been told that boys ought not to specialise at school, as if the sixteen or seventeen hours a week spent at classics was not more specialisation than the ten or twelve hours' science which was recommended. One might expect that, in these more enlightened days, more parents would rebel against a medieval system of education, but as a rule a parent does what he is told.

He lets the boy specialise in classics, although his future career may require a scientific training. In a very large number of cases men have come to me, both at the Imperial College and at Oxford, who want to be doctors, engineers, and the like, who have done little or no science, even when the schools from which they came were exceedingly well equipped for science teaching. In nearly every case the reason was the same, the parent had consulted the classical master, and taking what he thought was an expert opinion had decided to let his boy spend his time on classics. I say "spend," not "waste," for it really is rather a pleasant thing to have a knowledge of Latin and Greek. It is pleasant, and even sometimes useful, to know the derivation of words, but since, if we may accept an estimate quoted by Emerson, five-eighths of the words in English are not derived, either directly or indirectly, from the classical languages, the argument would be much stronger in favour of boys learning AngloSaxon. Latin and Greek ought to be regarded as luxuries, not as essentials, in education. It is to be hoped that in the near future there will be an organised revolt of British parents, and that they will demand that their boys shall be taught what will be of use to them afterwards, modern languages, including English, science, and mathematics. I suppose it is too much to hope that the new Education Bill, since apparently it is to touch the public schools, will help in making the education given in them more practical, doing, in fact, what classical masters will not, and science masters and parents cannot do.

The number of clever boys in any class is quite small. By cleverness I do not mean the capacity for learning; real cleverness, I take it, is the almost automatic power of picking out the essentials from a mass of inessentials, getting, in fact, to the root of the matter at once. Now it is too frequently the boy with a good memory, and that alone, who is picked out of the elementary school and sent on his upward way as something out of the common. Such boys have, of course, their proper and useful place in the scheme of things, but they are not going to do great things in the world. It is the other kind of cleverness that the country needs at the top, but there must be more than this cleverness even; the boy must have grit besides. He must be able to struggle and fight his way up, and, for this reason, let us earnestly hope that all the difficulties will not be cleared away. It is a ladder we want, not a moving staircase.

It is more and more common for the public-school boy to choose an engineering career, and it will be well for science masters to guard parents against sending boys into works, say at the age of sixteen, with an insufficient mathematical and scientific basis. Many engineers, and successful men, too, have recommended this course, saying the boys can pick up their mathematics and science for themselves.

The best course for an aspiring engineer is that he should have two years of good practical mathematics and science in properly equipped engineering labora- tories, and when he gets into works he will have the seeing and understanding eye. The last two years of his school life should be mainly devoted to mathematics, chemistry, physics, and both French and German, of which languages he should have a speaking as well as a reading knowledge.

I wish it were possible to include among possible careers for science boys the home Civil and the Indian Civil Services, for it is undoubtedly the case that those services would benefit greatly by such inclusion. The regulations at present in force, however, give too great an advantage to the classical boy. Out of the 6000 marks which it is possible for a candidate to aim at no fewer than 4400 are assigned to the subjects ordinarily included in a classical training. These marks are given for Latin, Greek, Roman and Greek history, logic and psychology, and mental and moral philosophy. Against these a science man can, as a rule, offer only lower mathematics and two science subjects, aggregating two thousand marks less. It is true that he might learn two more science subjects up to the not very high standard required, and that would add another 1200 to his possible marks. If he did so, however, and failed to get in, he would not be fit for any scientific career, except perhaps an inferior teaching post. The standard of the subjects in this examination is too low for it to be of use to him in any way, except it be supplemented in one subject by two years more advanced study. If science men are desired for these two great public services a much higher standard in at most two science subjects should be demanded, with a corresponding increase in the total marks attainable.

For those boys who have made physics their chief study at school and at college, there are fewer careers open than to those who have specialised in other branches of science. But I understand that aviation is going to bring this branch of science into prominent and practical usefulness. If one thinks also of the number of meteorologists in this country and its dependencies, it is obvious that here is an outlet for the physicist. The main bulk, however, of physics men become teachers.

To the chemist many avenues are open, and this is largely due to the awakening of the manufacturer to the usefulness of research work in all directions. I need not again recall to you the contrast of the German works and our own, but it would certainly be no exaggeration to say that, even now, for every industrial research chemist in this country there are twenty in Germany. However, there is no doubt that in the last five years the number of works chemists, of the research type, has enormously increased. It is for us who teach the boys and men to see that this most healthy movement, which is of Imperial importance, is not checked by the poor quality of the men sent into the works. Unless they are men with a natural aptitude for investigation and have been properly imbued with the research spirit, both at school and at college, it will be nothing less than a great misfortune for the country.

\section{UNIVERSITY AND EDUCATIONAL INTELLIGENCE.}

Cambridge.-Mr. G. R. Mines, of Sidney Sussex College, has accepted a temporary post as demonstrator of physiology in the University of Toronto. He will return to Cambridge about the middle of May.

Announcement is made that part i. of the examination for the diploma in psychological medicine will begin on Tuesday, June 2 , and part ii. on Tuesday, March 31. The examination for part i. will be held in Cambridge; that for part ii. will be held in London. The acting director of the observatory gives notice

NO. 2308, VOL. 92] 